\title{
Procesos de identidad en estudiantes de secundaria de Jalisco
}

DOI: https://doi.org/10.32870/dse.v0i8.307

\author{
Gloria E. Briceño Alcaraz*
}

\begin{abstract}
Resumen: Este artículo de investigación hace referencia a ciertos aspectos de la conformación de la identidad de un grupo de estudiantes de secundaria, pertenecientes a circuitos semiurbanos (Degollado, Puerto Vallarta, Techaluta) y urbanos (Zona Me-tropolitana de Guadalajara 'ZMG') de Jalisco, México. Los datos aquí presentados derivan de un estudio más amplio que exploró algunas prácticas de consumo cultural que inciden en los estilos de vida de esta población estudiantil. A través del artículo se ana-lizan algunos de los significados que los adolescentes le atribuyen a su experiencia durante su paso por la secundaria, para ello se propusieron cuatro dimensiones que hacen referencia a los procesos de individualización de los entrevistados: autopercepción, satisfacción consigo mismo, percepción de integración a la escuela y la visualización de su proyecto de vida. El instrumento para la recolección de los datos fue la entrevista a profundidad, teniendo como metodología el estudio de casos múltiples. De parti-cular interés fue explorar los significados sobre la escuela, la familia, la vocación y su ambiente social, en donde los medios de comunicación juegan un papel importante para comprender los nuevos estilos de vida y las maneras como los jóvenes tramitan los procesos de individualización, concepto clave en el estudio de las identidades contemporáneas. Palabras clave: identidad, escuela, cultura, individualización, estilo de vida.
\end{abstract}

\begin{abstract}
This research paper refers to certain aspects of the formation of the identity of a group of high school students belong-ing to semi-urban (Degollado, Puerto Vallarta, Techaluta) and urban circuits (ZMG) from Jalisco, México. The data presented here are part of a wider study that explored some cultural consumption practices that affect the lifestyles of this population. This article discusses some of the meanings that adolescents attribute to their experience during their lives at school, for it was pro-posed four dimensions that refer to the processes of individualization of respondents: self-perception, self-satisfaction, percep-tion of the environment and integration to institutions as school, as well the visualization of a life project. The instrument for data collection was the interview, with the methodology the multiple case study. Of particular interest was to explore the meanings of school, family, vocation and social environment in which the media play an important role in understanding the new lifestyles and the ways in which young people handled their processes of individualization, a key concept in the study of contemporary identities. Key words: identity, school, culture, individualization, life style.
\end{abstract}

\section{Introducción}

Los adolescentes y jóvenes mexicanos han venido cobrando cada vez mayor relevancia como sujetos y objeto de estudio, debido a su papel protagónico como actores sociales que se expresan y empoderan en nuevos espacios informales, aquellos en los que operan los medios digitales de comunicación y mass media. La ampliación de esos espacios de interacción comunicativa y su consiguiente apropiación simbólica, contribuyen a configurar una rica gama de subjetividades juveniles,

*Doctora en educación (SNI I), profesora e investigadora adscrita al Centro de Investigaciones Pedagógicas y Sociales (CIPS) de la Coordinación de Formación y Actualización Docente/Dirección de Posgrado e Investigación Educativa. Miguel de Cervantes Saavedra no. 286, Col. Lafayette, C.P. 44150, Guadalajara, Jalisco, México. Dirección electrónica de autora: evora@prodigy.net.mx 
que han desplazado los antiguos cartabones atribuidos a los adolescentes desde las instituciones educativas, para quien el escolar fue tan sólo un "sujeto de la educación", pero no un actor y creador de conocimientos con significados propios. Hoy difícilmente se puede seguir sustentando tal concepción del educando a la luz de las evidencias que aquí y en otros estudios se presentan.

Este artículo pretende analizar algunos de los significados que un grupo de adolescentes - de contextos urbano y semiurbano - le atribuye a su experiencia de vida durante su paso por la secundaria, se enfocará en conocer la percepción que tienen de sí mismos a partir de las representaciones que tienen de la escuela y la mediación de los otros (redes sociales, pares, amigos, figuras de autoridad); intentando explorar con ello, ciertos procesos de individualización relacionados con su edad durante este periodo escolar, en medio de un contexto amplio de aceleradas transformaciones sociales y culturales, como las que vive nuestro país y el mundo.

¿Cómo podemos entender el concepto de individualización? Se dice que el tránsito de la sociedad industrial a la etapa de "modernización reflexiva" transformó sustancialmente la relación individuo-sociedad, reconformando así al sujeto bajo un nuevo signo: el de la individualización (Beck, Giddens y Lash, 1997)'. Estos cambios han influido a su vez en la manera como se conforma la identidad del sujeto en su paso por el periodo juvenil, de tal manera que este proceso no se le puede comprender simplemente como de tránsito de la niñez a la vida adulta como antes se hacía, sino como una etapa de "moratoria indefinida", donde el sujeto busca por sí mismo los soportes para crear los referentes de una identidad siempre en desplazamiento y por lo tanto, abierta (Brater, 2000).

A continuación abordaré algunos hilos conductores de mi análisis, explicitando ciertas condiciones sociales y culturales que considero arrojan luz sobre los procesos de construcción de las identidades juveniles, las cuales tienen que ver con el papel relevante que asumen los jóvenes como actores del entramado sociopolítico nacional y mundial, empoderamiento que captura el interés de las ciencias sociales por su circunstancia y condición novedosa.

En general se puede afirmar que en América Latina el tema de los jóvenes como objeto de análisis, denota la preocupación de nuestra sociedad por este segmento de la población y su destino, así lo demuestran los diversos estudios que lo abordan desde las políticas públicas (Hopenhayn, 2003), la producción cultural y el capital escolar (Morduchowicz, 2004), procesos de individualización juvenil en Argentina (Tiramonti, 2004), configuración de culturas juveniles (Reguillo, 2000), nuevos circuitos de migración juvenil (Ibarra, 2011) y conformación de bandas urbanas (Marcial, 2011) entre otros.

1 Este concepto alude al sujeto como "actor, diseñador, malabarista y director de escena de su propia biografía, identidad, redes sociales, compromisos y convicciones"; Beck sostiene que los individuos contemporáneos son liberados de sus anclajes tradicionales que proveían las estructuras de la sociedad industrial para ingresar a la sociedad del "riesgo". Por lo tanto, la construcción de la individualidad en el mundo actual es un imperativo sin alternativa. 
Existen varias razones por las que el fenómeno juvenil se posiciona como tema emergente en las ciencias sociales y la educación, entre ellas destaca principalmente el desbordante desarrollo y consumo de las tecnologías digitales que acompañó la transición al XxI, donde las redes sociales (web 2.0) han captado el mayor número de usuarios. Esa veloz transformación y refinación tecnológica de los medios de comunicación dio origen a fines del siglo pasado a la llamada "sociedad del conocimiento", fundada sobre un nuevo tipo de capital: el intelectual, que se difunde a todo el mundo con la dinámica que imprime la globalización (Castells, 1998; García Canclini, 1999).

A partir de entonces, el conocimiento adquiere una centralidad en los sistemas educativos mundiales, ya que para hacer frente a los grandes desafíos de las sociedades modernas, se requiere desarrollar en los educandos las capacidades de innovación, creatividad e imaginación, componentes fundamentales del capital intelectual (Tedesco, 2000; Rifkin, 2002 y Hopenhayn, 2003). Tal meta está constituyendo todo un reto para nuestro país - como hoy lo vemos - con el tema de la reforma educativa, pues requiere transformar a profundidad las concepciones y competencias de maestros, metodologías, estrategias y tecnologías educativas.

Alrededor del uso y apropiación de los medios de comunicación digitales se conforman variedad de fenómenos sociales que, en su conjunto, condensan un horizonte cultural (zeitgeist) de implicaciones impredecibles, que va más allá de las meras transformaciones económicas y sociales, pues implica la interiorización de un mundo objetivado de cierta manera y bajo las condiciones que impone la cultura tecnológica; es decir, lo que se vive hoy son hechos sin precedente — nuevas experiencias - que reconstituyen las subjetividades y transforman la organización de la vida cotidiana de los sujetos y de los grupos sociales. Es en particular esta generación de jóvenes a quienes les toca vivir esta avalancha de cambios e incorporar a sus biografías los nuevos significados de las tecnologías comunicativas, como parte de su proceso de individualización. Son ellos quienes nos enseñan a los adultos cómo perderle el miedo a las tecnologías y saberlas usar con destrezas nuevas, transformar nuestros hábitos de comunicación social a través de nuevos dispositivos y aplicaciones con las que accedemos a redes de significados y maneras de relacionarnos entre todos, más allá de la historia familiar, estratificación social, capital cultural y escolar de los sujetos. Estos son los jóvenes que nacieron, como lo expresa Margaret Mead, en un "nuevo mundo" en el cual, son ellos quienes nos conducen como expertos cicerone:

...la liberación de la imaginación del hombre respecto del pasado depende, a mi juicio, del desarrollo de un nuevo tipo de comunicación con quienes están más hondamente comprometidos con el futuro: los jóvenes que nacieron en el nuevo mundo (Mead, 1980/1970: 122).

Si bien es cierto que ese "nuevo mundo" tiene visos de encantamiento generalizado, no se debe perder de vista las condiciones estructurales que lo alientan pero también lo condicionan. Como Bauman (2008) señala, este tránsito o relevo de cosmovisiones trastocó de manera profunda los va- 
lores de una sociedad tradicional, fundada en una ética del trabajo y del esfuerzo asalariado (aquella de nuestros padres y abuelos en la que existía una relación equilibrada de "necesidades-esfuerzo personal", y donde el rol protector de "Estado benefactor" infundía un sentimiento de confianza generalizada) por otros valores — que según el autor- conforman: la estética del consumo, la nueva racionalidad que predomina en el horizonte cultural actual. El surgimiento de este tipo de sociedad se explica justamente, por el tránsito hacia la modernidad tardía, en donde las instituciones tradicionales cedieron su espacio a los intereses del libre mercado y dejaron a los individuos a cargo de sí mismos; es decir, en una vulnerabilidad del sujeto frente al mercado donde el Estado-Nación deja de regular las relaciones; en esas condiciones el sujeto tiene que construirse a sí mismo.

En su etapa presente de modernidad tardía — esta segunda modernidad, o posmodernidad—, la sociedad humana impone a sus miembros la obligación de ser consumidores. La forma en que esta sociedad moldea a sus integrantes está regida, ante todo y en primer lugar, por la necesidad de desempeñar ese papel; la norma que les impone, la de tener capacidad y voluntad para consumir (ibídem: 44).

Habría que añadir, que ese mismo vector de cambio cultural reforzado por el desarrollo tecnológico y el proceso de globalización, remarcó como veremos más adelante, las asimetrías ya existentes entre aquellos jóvenes que tienen acceso a los bienes de consumo digital y cultural y los que no la tienen aún, debido al contexto donde habitan; es decir, entre los jóvenes de las grandes urbes y aquellos otros quienes por vivir en zonas rurales con pobre infraestructura, no tienen acceso a ellas.

¿En este panorama dónde queda la escuela? Se ha señalado, en distintos estudios, que el mundo contemporáneo que vivimos obliga permanentemente a una redefinición de estrategias y prácticas sociales, para las que no siempre es útil el bagaje cultural o escolar anteriormente conseguido (Tiramonti, 2004). Partiendo de lo anterior, y en lo que concierne a los jóvenes y adolescentes escolarizados, su experiencia de vida a temprana edad les muestra que hay dos realidades o mundos que corren paralelos con ocasionales cruces entre ellos, por una parte está lo que aprenden en la calle (cultura informal) y por el otro, el mundo de la escuela (Villalpando et al., 2012). Ambos contextos de aprendizaje aportan las significaciones, representaciones y conocimientos que los sujetos interiorizan conformando así nuevas representaciones de esas "realidades", a veces coincidentes pero generalmente contradictorias. El resultado de esa disociación de mundos se refleja de varias maneras: en la desvinculación de los aprendizajes escolares con las demandas específicas de la sociedad, en el persistente problema de deserción escolar en el nivel medio superior (alrededor de los 15 y 16 años), en la creciente dificultad de insertarse en los circuitos productivos al término de los estudios y recurrir a la migración como puerta de salida, como en el caso de los contextos rurales de México, y frente a todo eso o pese a ello, los adolescentes están obligados a la construcción de sus proyectos de vida (Ayala, 2001; Briceño, 2011). 
La incompatibilidad de mundos de vida crea las tensiones entre una generación que mira al futuro con el alcance de los medios electrónicos y, la precedente que por no haber tenido la experiencia, desconoce el camino y no sabe por lo tanto guiar a los "jóvenes del nuevo mundo", parafraseando a Margaret Mead.

Los jóvenes son heraldos del futuro en un mundo plagado de incertidumbres, y por lo mismo, son considerados como el grupo más vulnerable que habría que saber comprender y acompañar en su desarrollo, hasta que alcancen la mayoría de edad y logren su inserción en la sociedad (CEPAL/ CELADE, 2001). De ahí la pertinencia de analizar cómo los adolescentes significan sus vivencias personales durante su paso por la secundaria, cómo negocian el acoplamiento de esos dos mundos paralelos sobre los que necesariamente tienen que transitar para lograr constituirse en individuos; es decir, configurar su identidad social.

Sabemos por los estudios ya clásicos, que la escuela en su tarea formativa despliega de manera subrepticia, a través del currículum oculto, procesos socializadores tendientes a homogeneizar, estandarizar y fortalecer las subjetividades de los alumnos en el transcurso de la educación básica, con el fin de lograr su adaptación funcional al medio y responder a las expectativas familiares (Bourdieu y Passeron, 1977; Torres, 1992).

Conviene por lo tanto, indagar las identificaciones y/o rechazos que suscita en los adolescentes el papel uniformador de la escuela, como transmisora de conocimientos legitimados, frente a la opción abierta de diversificación y diferenciación que ofrecen los medios en la conformación de las subjetividades juveniles.

Diversas investigaciones coinciden en señalar que el desajuste entre las condiciones estructurales y la falta de oportunidades de trabajo para los jóvenes en nuestro país, transforma y diversifica la manera como éstos se incorporan a la sociedad; de tal suerte que las condiciones actuales hacen obligatorio el uso combinado de recursos formales e informales (INMJ, 2009). Lo cierto es que la escuela despierta resistencias y desinterés en una gran parte de los jóvenes debido - entre otras cosas- a que ya no es vista como la instancia que les puede asegurar un lugar en la sociedad, pero más que eso: donde pueden ganar más dinero de manera inmediata. La escuela, como mecanismo de movilidad social se aletarga ante una sociedad sostenida por la estética del consumo que privilegia otro tipo de valores; de ahí que la inserción social de los jóvenes de hoy se tramite por vías y estrategias alternativas que les permiten seguirse desarrollando a como dé lugar, sea con la opción ya tradicional de migrar hacia "el norte" (Meza y Pederzini, 2008) o bien, desarrollando una actividad surgida desde los medios de comunicación y redes sociales (modelo, disc jockey, cantante, etcétera).

\section{Método}

Se eligió el diseño de "estudio de caso múltiple", para analizar el material aportado, en las entrevistas a profundidad realizadas a 15 informantes de ambos sexos, pertenecientes a cuatro circuitos 
clasificados como semiurbano (Techaluta, Degollado, Puerto Vallarta) y urbano de Jalisco (Zona Metropolitana de Guadalajara).

Metodológicamente, el estudio de caso se adecua a las necesidades de analizar este grupo de adolescentes como una entidad que comparte ciertos elementos en común, pero que en la medida que se profundiza, ofrece la posibilidad de identificar las singularidades relacionadas con cada caso en particular (subjetividad) ya que toma en consideración el contexto al que pertenece cada uno o donde el fenómeno se desarrolla (Yin, 1994; Stake, 1995). El procedimiento empleado fue el siguiente: los casos se analizaron primero en relación con los respectivos contextos (urbano, semiurbano) a los que pertenecían los sujetos, y posteriormente, se realizó una comparación en su conjunto; de tal manera que se pudieron identificar en un primer nivel de análisis — y por grupoalgunas similitudes y diferencias en sus enunciados que conformaron una codificación inicial, la cual se transformó con el siguiente análisis de ambos grupos, a la construcción de las categorías finales con las que se analizó el total del material recabado. Las edades de los informantes oscilaron entre los 11 y 15 años, los cuales estaban adscritos a diversos grados del nivel secundario.

Las siguientes categorías se obtuvieron en el proceso de análisis descrito, y expresan con diversos matices que son propios del contexto social y familiar del cual provienen los jóvenes, algunos aspectos de su subjetividad pero también de sus percepciones y representaciones del mundo de vida que los circunda.

1. Autopercepción (cómo se percibe asimismo el entrevistado).

2. Satisfacción consigo mismo a partir de sus actividades y acciones relacionadas con su rol social y género.

3. Percepción de la escuela y del medio social.

4. Visualización de un proyecto de vida (a mediano o largo plazo).

Se utilizó la entrevista a profundidad para realizar el rastreo de las dimensiones subjetivas descritas, con la consideración de que lograr eso, dependió de la facilidad de expresión y desenvolvimiento que los informantes tenían frente al micrófono y al entrevistador. El lugar de la entrevista fue por lo general en la escuela, patio de recreo o jardines, y sólo en tres casos se realizó en la propia casa de los informantes.

Se partió de una pregunta abierta que pretendía ser detonadora de la conversación e incitara a la reflexión sobre algunos aspectos de la propia subjetividad en esta etapa de la vida: "¿Quién es...?". Tal cuestionamiento implica por principio un alto grado de reflexión y autoconocimiento por parte del sujeto, que aunque la respuesta pueda ser aún provisional y apresurada, denota el vórtice de tensiones, identificaciones y expectativas que conviven en la conformación del individuo en ciernes. 
Mientras que para unos contestarla puede ser un trámite de identificación y de adscripción que se resuelve con una palabra:" estudiante", "adolescente", "chavo", etcétera; para otros, representa un verdadero ejercicio de autoexploración en donde los atributos contrastantes, la broma inmediata y la etiqueta fácil, son la mejor manera de presentarse en un primer momento a los demás. Sin embargo, de ahí pasan a otro nivel de reflexión en donde la autodefinición cobra una importancia singular pues en el intento de responder tal pregunta se revelan a los otros y a ellos mismos, de una manera diferente que no conocían o al menos no habían verbalizado, como lo vemos a continuación.

\section{Resultados}

A través de los siguientes extractos de las entrevistas, podemos observar que autodefinirse resulta casi siempre un ejercicio difícil para cualquier adolescente por la profunda reflexión que implica, pero también porque se conoce menos de sí mismo que de los demás. Lo anterior se denota por los atributos ambiguos utilizados, sus momentos de silencio y sus exabruptos. La respuesta más rápida la dieron los chicos con adjetivos que constituyen la representación que tienen de sí mismos y que está en relación con el rol que en ese momento desempeñan: "soy un joven" o "soy un estudiante" relacionadas con su edad y con su vida escolar. En contraste con las adolescentes, ellos prefirieron emplear enunciados ambiguos y descriptivos de una subjetividad oscilante que va de las emociones a estados de ánimo contradictorios en una misma frase tales como "alegre, floja, agradable, amigable, nerviosa, honesta, creativa, matadita". Sus descripciones fueron, como veremos, un poco más largas y por momentos vacilantes, pero indudablemente más reflexivas, con atributos chispeantes pero contrastantes, que dejaban caer como sopesando cada palabra, dando la sensación de una frase inacabada:

Clara (13 años, ZMG): Pues hay muchas formas de decirlo ¿no?, porque yo pienso que puedo decir mi nombre, mi edad, mi altura, pero ya decir cómo soy, pues ya es otra cosa, soy muy alegre, soy este... entre responsable, pero también soy muy atolondrada, se me olvida todo, soy muy floja y... o sea soy muy amigable y lo que quieras pero por otra parte soy como muy agradable y por otra soy muy reservada y así... Yari (12 años, ZMG): Yo me definiría como una persona responsable, una persona pues libre, una persona respetuosa, ¿cómo seré? Valiente, animada, se podría decir, mmmmm interesante, ¿cómo me podrían decir?... a veces de burla "matadita", porque siempre tengo muy buenas calificaciones, mmmm como más me podría definir... como deportista, creativa, pues creo que eso ya sería todo.

Ruth (14 años, Techaluta): Pues yo soy este... me gusta estar con mis amigas, convivir, soy muy alegre y me gusta convivir con la gente.

Toño (14 años, Degollado.): Pues... yo digo que un muchacho sencillo, mmm... trabajador, estudioso.

Basilio (12 años, Puerto Vallarta): Pues que es un niño, sincero, chaparrito más o menos, no sé, no me conozco bien pues. 
Daniel (15 años, Techaluta): Yo le diría que Daniel es un joven, que estudia secundaria que trata de comportarse bien, de llevar una vida... como le podría decir, como de cualquier otro joven pero alejado de los vicios y de todo eso del vandalismo.

En este primer momento resulta claro advertir que sus enunciados nos remiten a una apropiación diferenciada de los signos y referentes culturales mediada por el género ${ }^{2}$; es decir, el sujeto desde su identidad sexual y de clase social va construyendo su singularidad como individuo, a través de un ejercicio que implica reconocer y negociar las fronteras entre el Yo y los Otros, de prácticas y enunciados con los que sienten se identifican más, que los describen en sus contradicciones, en sus deseos, en eso que están queriendo llegar a ser pero no lo pueden aún enunciar. En sus expresiones podemos advertir de alguna manera, los matices y contrastes con los cuales buscan marcar las diferencias y contornos de lo que conoce de sí mismo. Advertiremos en las siguientes viñetas que el estudiar una carrera entra en los planes de la mayoría; sin embargo, volvemos a encontrar en ambos géneros sutiles diferencias cuando expresan sus opciones; mientras para los chicos su proyecto de estudio se resuelve con una carrera que eligen sin dudar, en el caso de las chicas la elección se hace difícil ante dos o más posibilidades que perciben como igualmente atractivas. Parece que en el caso de las chicas las situaciones son analizadas considerando aspectos o relaciones que son para ellas igualmente importantes (familia, lugar, amigos, etcétera), impidiéndoles en un momento dado decidirse rápidamente por alguna opción sin haberla cabalmente sopesado.

Encontramos también en sus enunciados, la convivencia de diversas voces que nos descubren algunos rastros de socialización que han dejado las instituciones (familia, escuela), por ejemplo, "soy trabajador", "estudioso", "de bien", "alejado del vandalismo", "responsable", que podríamos tomar como indicio de la interiorización de ciertos valores que postula la escuela como válidos y que están íntimamente relacionados con la ética del trabajo propia de las sociedades tradicionales como la nuestra. Hay que decir que aunque cabría esperar este tipo de respuestas en algunos de ellos (dado que estamos con escolares), no deja de sorprender la convicción con la que lo expresan.

De igual forma, es posible identificar en estos jóvenes las primeras configuraciones de una vocación aún incierta e indefinida pero, ya presente en el imaginario de algunos de ellos ${ }^{3}$. Esto bien puede indicar que el proyecto personal inicia su trazo en el imaginario juvenil antes de lo esperado en muchos casos, lo que nos conduce a pensar que los procesos de individualización comienzan justo con este importante ejercicio imaginativo:

2 El concepto de género es definido como "el conjunto de ideas, representaciones, prácticas y prescripciones sociales que una cultura desarrolla desde la diferencia anatómica entre mujeres y hombres, para simbolizar y construir socialmente lo que es "propio" de los hombres (lo masculino) y lo que es "propio" de las mujeres (lo femenino)" (Marta Lamas, 2002: 131).

3 Estoy utilizando el término imaginario en el sentido psicoanalítico otorgado por Castoriadis, que da cuenta de la articulación entre la psique (subjetividad) con la sociedad y las significaciones imaginarias. Ver Yago Franco (2003), Magma. Cornelius Castoriadis: psicoanálisis, filosofía, política. Buenos Aires: Biblos. 
Laura (15 años, Degollado): algo que me gustaría mucho estudiar seria la profesión de biología, pero hay problemas económicos, a veces se presentan... y también es que yo no quiero estar alejada de mis padres, de mi familia y aquí (en Degollado) seamos sinceros, no hay trabajos para una licenciada en biología.

Clara (13 años, ZMG): Quiero ser psicóloga o estudiar ciencias de la comunicación, una de esas dos... me imagino más como mi mamá, dando conferencias y así, pero por otra parte me imagino estando en la tele también, ya sea como psicóloga o dirigiendo un programa.

Ramiro (15 años, ZMG): De adulto, pues me veo trabajando, o sea trabajando contento de lo que me gusta hacer, pienso estudiar arquitectura entonces yo creo que eso me agrada, pienso hacer eso (...).

Yari (13 años, ZMG): me gustaría la gimnasia como un proyecto pero aparte tengo como tres carreras en mente que serían... comunicación, diseño, o psicología que son las tres carreras que me gustarían.

Toño (12 años, Degollado): Pues de grande quisiera ser yo doctor o licenciado, si más o menos una carrera... Si, licenciado, me lo dijo mi tío que hay muchos tipos de licenciado, me dijo que hay un tipo de licenciado que cuenta dinero, voy a ver...

Daniel (15 años, Techaluta): Si le echo ganas quiero ser un odontólogo profesional, y quisiera trabajar en una clínica o tener mi propia clínica y quiero especializarme en cirugía para niños, en odontólogo... Yo le ayudo a mi papá a recoger y pelar pitayas... mi mamá también le ayuda a pelar... pero como ahorita ya viene el temporal de lluvia, pues siembran maíz, frijol y jitomate.

A través de estos registros, se desprende que la función de socialización realizada por la escuela parece ser exitosa, e inclusive en apariencia homogénea, ya que en sus voces se ven reflejados los marcos normativos que se perciben como útiles para la construcción de una vocación futura, por lo que podemos suponer que la escuela aún significa para ellos un medio para independizarse en su vida adulta y ser productivos. Esas expectativas, que son seguramente resonancias de las de sus padres, refuerzan su permanencia en la escuela y dan significado a sus proyectos de vida, como se observó en ambos contextos (semiurbano y urbano). Sin embargo, también encontramos algunas voces que cuestionan el para qué ir a la escuela, y dan cuenta de una individualidad que se resiste a ser uniformada del todo; en este grupo encontramos que las chicas expresan con más libertad ese sentimiento de resistencia y rebeldía:

Clara (13 años, ZMG): Siempre me ha dado mucha flojera ir a la escuela, creo que todo mundo va porque sus papás le dicen: tienes que ir y porque desde chiquito te dijeron: tienes que ir a la escuela y ya tienes esa mentalidad. Pero por otra parte, cuando veo a gente que no estudió - porque conozco muchos-; por ejemplo, a una amiga la corrieron y va a la secundaria abierta. Eso es un caos ¿no?, entonces si yo no quiero vivir tan mal debería estudiar, por eso es algo importante: ¡no quieres hacerlo, pero lo tienes que hacer y ya! 
Elidia (14 años, Degollado): ¿La escuela? me da sueño levantarme temprano y tener que venir a esforzarme a pensar... aunque en la copiadera más o menos me va bien (...) me dicen que soy relajienta, porque me gusta pintarme los ojos y a las monjas no les gusta eso... ellas son muy estresantes y delicadas.

Guadalupe (15 años, Degollado): Sí me gusta esta escuela, porque es divertida y porque no tenemos casi clases [risas] como tengo una maestra que tiene una enfermedad y se enferma mucho y no viene... y como yo no soy muy dada a las matemáticas por eso...

La escuela como vemos, representa — para una gran parte de los estudiantes — un trámite, obligado por los padres, que les demanda mucha de su energía y voluntad, como el de cumplir con los horarios y rituales; una práctica a la que se adhieren - no sin resistencias - a cambio de ciertas ganancias emocionales, que son importantes para ellos en ese momento de su existencia: corresponder a las expectativas de los padres, sentir el cobijo de la familia y compartir sus experiencias cotidianas con sus pares, acompañándose mutuamente en este tránsito de cambios sucesivos. Por todo ello, sigue siendo el espacio de interacción y diálogo intersubjetivo por excelencia, donde los jóvenes afiliados negocian y practican con sus pares diversas formas de ser, desear, pensar y poner a prueba determinadas aptitudes y actitudes propias de su generación. Es en ese sentido que se puede afirmar que los adolescentes, adscritos a la escuela, son los que tienen las mejores oportunidades para desarrollar en sus potencialidades y afectividades en un medio idóneo para la exploración social. En ese sentido confirma lo expresado por Reyes (2009) en cuanto a que, si bien la secundaria es un espacio de tensiones, en su interior también se gestan comunidades emocionales que favorecen los procesos de individualización.

En lo referente a como estos jóvenes tramitan sus relaciones con los demás, empezando por su propia familia, sus lazos afectivos y su impulso hacia la independencia, encontramos que a diferencia de lo que es una clara tendencia de búsqueda de autonomía fuera de la familia, por parte de jóvenes de otras latitudes (particularmente en Estados Unidos y Europa), los adolescentes jaliscienses prefieren el lazo emocional con su contexto social y familiar que salir fuera, lo que se traduce en un fuerte sentido de pertenencia a la región.

Es interesante cómo estos adolescentes rescatan las cualidades más positivas de su entorno y las convierten en fuertes asideros de su actual etapa, lo que hace pensar que sus deseos de independencia aún no son tan fuertes como para pensar abandonar el "terruño" familiar por razones de estudios. La inusual tardanza en la aparición de sus procesos de expansión y autonomía que fraguan la individualización, parece deberse a que las familias en nuestra sociedad mexicana retienen por más tiempo al adolescente, prolongando así una etapa de dependencia que puede obstaculizar la emergencia de nuevas formas de desarrollo y expansión emocional que son propias en esta edad. Por lo que de experimentarlas, éstas se verán reflejadas de manera ambigua y contradictoria. 
Basilio (12 años, Puerto Vallarta): Pues se me hace bonito Puerto Vallarta, me quisiera quedar aquí... pues porque se me hace bonito a comparación de otros lugares que he ido, lo que me gusta de Puerto Vallarta y a la vez porque no me quiero ir, aparte de mis amigos, es porque aquí está toda mi familia... me gusta esta cerquita de los lugares que me gustan; que vamos al malecón, me gusta porque esta bonito, por el entrenamiento, el clima, las playas.

Flor (13 años, Degollado): De Degollado me gusta mucho su historia, la cantera, todo eso y la música que hacen aquí los señores, porque también hay artistas aquí... mucho, me gusta mucho su cultura.

Toño (14 años, Degollado): Me gustaría ir a Guadalajara de visita, o sea a México, a varias partes... me gustaría ir nada más a visitar pero, para quedarme no, solamente aquí. Yo pienso que Degollado está bien, porque pues aquí tienes todo, tienes campo para divertirte, hay trabajo yo digo que está bien.

Daniel (15 años, Techaluta): La vida aquí no es tan difícil, de hecho es más fácil que en la ciudad (...) Sin embargo pienso concluir aquí la preparatoria Colegio de Bachilleres e irme a los Estados Unidos para acabar mis estudios. Allá están mis abuelos por parte de mi mamá, ellos me han dicho que si me quiero ir a estudiar me ayudan, también tengo a mis tíos que también me lo han dicho... me gustaría irme pero a la vez no, porque tengo aquí a mis papás y no me gustaría dejarlos.

La configuración del proyecto de vida en esta edad, depende de qué tan estable y seguro perciban el medio ambiente social donde se desarrollan los adolescentes, de las garantías que las instituciones les ofrezcan para conseguir sus metas y por supuesto, del apoyo de su entorno familiar. En ese sentido, encontramos en algunas de las siguientes viñetas una variedad de registros que van desde la toma de conciencia de la problemática ambiental o cambio climático hasta críticas al gobierno por la falta de seguridad y empleo. Al externar sus percepciones y preocupaciones de manera franca y abierta, nos muestran una faceta poco explorada del adolescente consciente de las problemáticas mundiales y regionales, con una gran preocupación por la conservación del medio ambiente y el futuro de la humanidad.

Yari (13 años, ZMG): Pues es que México se puede salvar por la diversidad y todas estas cosas pero, finalmente hay un problema, bueno muchos problemas que son como esto del narcotráfico, la lucha contra todo eso de las drogas, (...) pero va a ser lo mismo que el alcohol y van a terminar tomando una medidas como bien locas que te van a terminar metiendo siempre a la cárcel, entonces es como todo ilógico. Y luego que de todas formas toman y fuman desde chicos, la falta de empleo pues todo, es como que el gobierno es literalmente una basura...

Laura (15 años, Degollado): Francamente en algunas partes está lleno de inseguridad, pero yo pienso que eso se puede superar, se pudo superar que una mujer pudiera votar, que tuviera derechos, entonces creo que la inseguridad se puede superar, sobre todo si tienes ganas y entusiasmo.

Daniel (15 años, Techaluta): México tiene avances y tiene bajas, hace poco hubo una baja de la economía, poco a poco se tiene que ir restableciendo la economía si todos se apoyan entre sí (...) pues de echo des- 
cubro que si no cuidamos el planeta se va ir acabando, cada día más y más se va acabando... si todos nos ponemos a trabajar en beneficio del planeta lo podemos salvar.

Clara (13 años, ZMG): Depende... en avances tecnológicos, está muy bien, en así cosas súper bien, pero ya si me dices así como drogas, adicción y todo, no. O así como que el calentamiento global y a la contaminación, no.

La apropiación que han hecho los jóvenes de los dispositivos y medios de comunicación digital ha sido veloz y sorprendente para los adultos que no crecimos con estos instrumentos. Tanto es así que hoy se puede afirmar que esta revolución silenciosa no sólo no ha moldeado las subjetividades y estilos de vida, sino también la manera como aprenden; los adolescentes de secundaria nos muestran que pueden ser verdaderos autodidactas y guías de sus propios aprendizajes. Es por ello que podemos afirmar que las tecnologías y dispositivos digitales representan los nuevos andamiajes del desarrollo intelectual y social de los jóvenes, porque no sólo aprenden por medio de éstos, sino que construyen interacciones y descubren mundos de vida (Briceño, 2009, 2012).

Mientras otros países ya usan racionalmente las TIC en el ámbito escolar y con un propósito curricular definido, en el nuestro por el contrario, se limitan estas prácticas en las secundaria públicas como lo pudimos constatar en la encuesta aplicada en el Estado de Jalisco sobre consumo cultural (Villalpando et al., 2012). Durante el trabajo de campo, observamos que gran número de planteles - tanto urbanos como rurales - carecían de la infraestructura necesaria en equipo y conexión a Wi-Fi (con excepción de la dirección), razón por la que las "aulas de cómputo" no revisten el interés que deberían suscitar y por el contrario, su equipamiento es obsoleto y en mal estado, lo que ahí se les enseña en realidad son los programas Word y Excel. Esto ha significado un negocio para los cibercafé, donde los jóvenes se conectan a la red y navegan sin las miradas curiosas de los maestros y padres. ¿Qué hacen pues los adolescentes cuando se tiene la conexión en casa?, ¿cuál es el uso que le dan a la computadora y dispositivos móviles?

Guadalupe (15 años) No veo mucho tv... me la paso más en la computadora que en la tele... visito más el MSG o Myspace... a veces pongo fotos y mis primas me las comentan y en el MSG nomás veo quién está conectado o así los correos que me mandan... los maestros como de... navidad, saludos y todo eso... le dedico diario como una hora o media hora ¿la tarea? como unos $15 \mathrm{mn}$., porque nada más saco la información, lo leo, lo resumo y ya, lo copio y pego y luego lo imprimo.

Toño (14 años): El internet lo uso para divertirme ahí, contar chistes con mis amigos o eso... es lo que disfruto.

Javi (12 años): Sí, a veces vamos al ciber para chatear, o a veces los domingos vamos a la plaza y nada más eso es lo que hacemos los fines de semana. Casi nada más juego en mini clip y a veces me meto a mi correo a chatear y eso... 
Flor (13 años): El internet me parece que está muy bien porque ahora podemos sacar más información, sabemos más de la tierra, del mundo... lo uso para aprender más, me gusta mucho el arte y la música y todo eso. Tengo Messenger, Facebook pues chateo con mis familiares y mis amigos que ahorita no se encuentran en Degollado.

Daniel (15 años): Me gusta ir al ciber a meterme a las computadoras, investigar a veces casos que me llama la atención... casi uso más el internet, me interesa la ecología y la vida de las personas en distintos países... en el ciber estoy pues como una hora dos o tres día a la semana... el celular es para oír música, comunicarme con mis amigos, mi papá, nada más lo necesario.

Paola (13 años): En la escuela solamente me enseñan los programas Microsoft Word y Excel, pero yo sola aprendí a buscar la información y con mis compañeras... no, los maestros no conocen bien esto... además no nos dejan entrar al internet en mi escuela.

Vemos que "navegar" por la red, más que un mero entretenimiento, les representa la experiencia de saborear los primeros pasos hacia la libertad, más allá de los confines habituales en los que se mueven y que son fijados por los adultos y la institución. La conquista de un espacio propio, donde pueden decidir y controlar por sí mismos las coordenadas del tiempo y espacio, es la sensación que buscan repetir constantemente, la inmediatez de la comunicación, instantes en donde se vuelven a guarecer en su mundo. Perfeccionar las nuevas destrezas digitales y sentir que son los "dueños de sus acciones" les amplifica la experiencia de su propia imagen, les infunde seguridad. La telefonía móvil e internet dan justamente la posibilidad de navegar entre "burbujas de tiempo" que ellos dosifican entre tarea y tarea, entre la clase de un profesor que aburre y el WhatsApp del amigo, la respuesta no se hace esperar para deslizar los pulgares a la velocidad de la escritura Morse (Igarza, 2009).

Mientras que los contenidos y enseñanza de la escuela requieren de una atención continua y concentrada, los medios digitales favorecen la atención flotante, discontinua y desconcentrada de los detalles a profundidad. Esta contradicción de aprendizajes y competencias es lo que los educadores e investigadores deberíamos saber armonizar para la construcción de nuevo aprendizaje — situado en el contexto de la sociedad del conocimiento - pero de manera equilibrada.

\section{Discusión}

A lo largo de este artículo, derivado de algunos resultados de una amplia investigación sobre el consumo y cambio cultural de los estudiantes de secundaria en Jalisco, se rastrearon y exploraron algunos matices de las subjetividades de un grupo de adolescentes escolares de ambos géneros, con el fin de conocer cómo tramitan, negocian y acoplan los diversos significados y representaciones entre su mundo de vida y el mundo de la escuela, entre su propia percepción y los otros. Se propuso el concepto articulador de individualización para comprender el proceso que conlleva a la construcción personal de sí mismo, en una sociedad moderna pero contrastante en contextos culturales 
como la nuestra. Pudimos darnos cuenta de que más allá de las similitudes que comparten en conjunto como estudiantes y que la escuela pretende remarcar a través de diversos dispositivos (uniforme, procesos estandarizados de enseñanza, disciplina, etcétera), los adolescentes se empeñan de una $u$ otra manera en marcar sus diferencias entre ellos y los otros, en mostrar su individualidad en sus relaciones y en la manera de expresar sus deseos de lo que quieren llegar a ser en un futuro cercano.

En cuanto a la manera de percibirse a sí mismos, se destacan las diferencias de género más que las de contexto social (urbano, semiurbano); aquí encontramos registros contradictorios pero reflexivos con los que las chicas se autodenominan y reconocen a sí mismas como sujetos, indicando así una manera compleja de pensamiento no referenciado a una determinada adscripción escolar, sino a formas sensibles de experiencia que devienen en papeles protagónicos como actores sociales en ciernes. Contrastando con lo anterior, vimos la forma inmediata y sucinta que eligieron los chicos para autodefinirse, externando así un pensamiento lógico que excluye la contradicción por principio. Estas formas divergentes con las que los sujetos se enuncian son atribuidas ciertamente a la construcción de la identidad de género, cuya impronta la recibe de la cultura y es filtrada a través del lenguaje. Eso nos lleva a constatar que el desarrollo de la identidad social del sujeto surge en una etapa temprana con la consciencia de su rol (estudiante, amigo, alumno, amigo, etcétera) a partir de las múltiples interrelaciones con los otros.

Las diversas voces contenidas en los enunciados de estos jóvenes nos recuerdan que el sujeto forja su identidad a través de la palabra de los otros, y que su mundo subjetivo está por lo tanto, constantemente interpelado desde la otredad. En ese cruce de mundos de vida: el de las instituciones como la escuela, cuyas normativas son identificadas con el mundo adulto y el de la cultura informal (conformado por los pares, el ciber, las plazas, las calles), los adolescentes de circuitos semiurbanos como urbanos de Jalisco, tratan de encontrar consensos y acuerdos que les permiten cumplir con las expectativas familiares, pero abriendo cada vez más su vida hacia el exterior por medio de los pares, amigos, vivencias y experiencias mediadas por los medios de comunicación. Para estos adolescentes, su experiencia en la escuela tiene sentido en la medida que les permite vislumbrar una vocación a futuro y les confiere las herramientas conceptuales para la realización de sus metas; pero más aún, les brinda la oportunidad de interactuar diariamente con sus pares y amigos, y de construir nuevos significados sociales en medio de un ambiente predecible y seguro.

Un matiz de diferencia, registrado entre ambos circuitos, que quizás no quedó explicitado en las viñetas pero sí en el conjunto del material analizado, fue que en algunos jóvenes del circuito semiurbano de Jalisco (Degollado y Techaluta) sigue estando presente el imaginario de la migración como una ventana de oportunidades a las limitaciones de realización que dicen tener en su lugar de origen. Si bien hoy ya no piensan irse de "braceros", desean irse para completar su formación en el norte y convivir con sus primos que viven en alguna ciudad de Estados Unidos (Atlanta por ejemplo, donde la gran parte de los entrevistados de Degollado tienen familiares); así pues la cultura de 
la migración está fuertemente enraizada a través de la familia extensa, que alienta sus sueños de emigrar al terminar la secundaria.

Como una preocupación que gana espacio en la vida cotidiana de los adolescentes pudimos encontrar voces de preocupación sobre el medio ambiente y la seguridad en nuestro país, ello nos habla de un incipiente pero notorio despertar de la conciencia hacia estos temas por parte de estos adolescentes.

Por otro lado, si bien es cierto que las tecnologías digitales capturan la atención de los jóvenes, en este grupo el uso es racional y moderado. Más allá de eso, lo que es interesante apuntar es el significado que adquiere para ellos su uso; ya que como decíamos, a través de las redes sociales (particularmente el Facebook) ellos establecen experiencias de acompañamiento y comunicación que pueden ser aprovechadas para el desarrollo de formas de individualización. Sin embargo, para este grupo de jóvenes el papel de las interacciones cara a cara sigue siendo fundamental para establecer los vínculos emocionales.

Finalmente, si la individualización es un proceso de las sociedades modernas que implica la búsqueda de nuevos asideros con los cuales construirse como sujetos de identidad, sin los soportes usuales de las instituciones (familia y escuela), debemos admitir entonces que -al menos para estos estudiantes entrevistados- es un proceso que aún no se observa de manera uniforme como en otras latitudes, al menos no para el grupo del contexto semiurbano. Pero, si de cualquier manera este fenómeno es la tendencia mundial de las nuevas subjetividades juveniles, entonces debemos estar preparados.

\section{Bibliografía}

Ayala, S. (2001). “La deserción escolar: ¿un callejón sin salida?”. En: Matute, E. y R. M. Romo Beltrán (coord.). Los retos en la educación del siglo XXI. México: UdeG, pp. 77-101.

Bauman, Z. (2008). Trabajo, consumismo y nuevo pobres. Barcelona: Gedisa, $2^{\mathrm{a}}$ reedición.

Beck, U., A. Giddens y S. Lash (1997). La modernización reflexiva. Políticas, tradición y estética en el orden social moderno. Buenos Aires: Alianza.

Brater, M. (2000). "Escuela y formación bajo el signo de la individualización". En: Ulrich Beck (comp.). Los hijos de la libertad. México: Fondo de Cultura Económica, pp. 126-151.

Bourdieu, P. y J. C. Passeron (1977). La reproducción, elementos para una teoría del sistema de enseñanza. Barcelona: Laia.

Briceño, G. (2009). "El sujeto de la educación en red, una reconceptualización del entorno sociocultural”. En: Hernández, S. C. y A. Reynoso (comps.). La educación en ambientes virtuales, desafios para este siglo. México: CUCEA/UdeG, pp. 197-225.

— (2011). "Deserción y migración: correlatos de la realidad mexicana". En: Briceño, G. (coord.). Memorias del Simposio Internacional México Alemania 2011: Migración, desafios y posibilidades. Guadalajara: Prometeo editores, pp.85-99. 
Castells, M. (1998). La era de la información. Madrid: Alianza.

CEPAL/CELADE (2001). Vulnerabilidad y grupos vulnerables: un marco de referencia conceptual mirando a los jóvenes. Santiago de Chile: LC/L, p. 1588.

García, N. (1999). La globalización imaginada. Barcelona: Paidós.

Giddens, A. (1995). Modernidad e Identidad del Yo. El Yo y la sociedad en la época contemporánea. Barcelona: Ediciones Península.

Hopenhayn, M. (2003). Educación, comunicación y cultura en la sociedad de la información: una perspectiva latinoamericana. Chile: CEPAL/ECLAC.

Ibarra, M. (2011). "Nuevos circuitos de migración juvenil: de Coyula a Nueva York". En: Briceño, G. (coord.) Migración, desafios y posibilidades, Memorias del simposio México-Alemania. México: Prometeo, pp. 101-112.

Igarza, R. (2009). Burbujas de ocio. Nuevas formas de consumo cultural. Buenos Aires: La Crujía Ediciones.

Instituto Mexicano de la Juventud (INMEJ) (2009). Encuesta Nacional de la Juventud. México: Secretaría de Educación Pública. México: INMEJ. Centro de Investigación y Estudio sobre la Juventud.

Lamas, M. (2002). Cuerpo: diferencia sexual y género. México: Taurus, Alfagura.

Marcial, R. (2011). "Norteños vs. Sureños: adscripciones identitarias y rivalidades de grupo a partir del fenómeno migratorio entre jóvenes cholos de Guadalajara". En: Briceño, G. (coord.). Migración, desafios y posibilidades, Memorias del simposio México-Alemania. México: Prometeo, pp. 63-74.

Mead, M. (1980/1970). Cultura y compromiso. El mensaje de la nueva generación. Barcelona: Gedisa.

Meza, G. L. y V. C. Pederzini (2008). "Migración internacional y escolaridad como medios alternativos de movilidad social: el caso de México". En: Estudios Económicos. México: Universidad Iberoamericana, número extraordinario, pp. 163-206.

Morduchowicz, R. (2004). El capital cultural de los jóvenes. Argentina: FCE.

Reguillo, R. (2000). Emergencia de culturas juveniles. Estrategias del desencanto. Buenos Aires: Grupo Editorial Norma.

Reyes, J. A. (2009). Adolescencia entre muros. Escuela secundaria y la construcción de identidades juveniles. México: FLACSO.

Rifkin, J. (2002). La era del acceso. La revolución de la nueva economía. Barcelona: Paidós Ibérica.

Stake, R. E. (1995). The Art of Case Study Research. Thousend Oaks: Sage Publications.

Tedesco, J. C. (2000). Educar en la sociedad del conocimiento. Buenos Aires: Fondo de Cultura Económica. 
Tiramonti, G. (2004). "La fragmentación educativa y los cambios en los factores de estratificación". En: Tiramonti, G. (comp.). La trama de la desigualdad educativa: mutaciones recientes en la escuela media. Buenos Aires: Ediciones Manantial, pp. 15-46.

Torres, J. (1992). El currículum oculto. Madrid: Morata, $3^{a}$ edición.

Villalpando, M., G. Briceño, M. G. Castañeda y P. Elizarrarás (2012). Consumo y cambio cultural en estudiantes de secundaria en Jalisco. Reporte de investigación. SEP/CONACYT/SEJ. Guadalajara, México: Pandora.

Yin, Robert K. (1994). Case Study Research: Design and Methods. Thousand Oaks: Sage Publications.

Recibido: 30/09/13

Dictaminado: 14/02/14

Corregido: 16/02/14

Aceptado: 20/02/14 